\author{
버크셔종의 육질형질에 대한 유전모수 추정 \\ 정종현 ${ }^{*} \cdot$ 김철욱 ${ }^{2} \cdot$ 박범영 $^{3} \cdot$ 최종순 $^{4} \cdot$ 박화춘 $^{1}$ \\ ${ }^{1}$ 다산육종, ${ }^{2}$ 국립진주산업대학교, ${ }^{3}$ 농촌진흥청 축산과학원, ${ }^{4}$ 한국기초과학지원연구원
}

\title{
Genetic Parameter Estimates for Meat Quality Traits in Berkshire Pigs
}

\author{
Jong-Hyun Jung ${ }^{1}$, Chul-Wook Kim ${ }^{2}$, Beom-Young Park ${ }^{3}$, Jong-Soon Choi ${ }^{4}$ and Hwa-Chun Park ${ }^{1 *}$ \\ ${ }^{1}$ Dasan Pig Breeding Co. San 64-2, Gasan-ri, Eubnong-eub, Namwon-si 590- 831, Korea, ${ }^{2}$ Department of Animal Resources \\ Technology, Jinju National University, Jinju 660-758, Korea, ${ }^{3}$ National Institute of Animal Science, RDA, 77 Chuksan-gil, \\ Gwonsun-gu, Suwon 441-706, Korea, ${ }^{4}$ Korea Basic Science Institute, 113 Gwahangro, Yuseong-gu, Daejeon 305-333, Korea
}

\begin{abstract}
Swine industry in Korea plays an important role in providing the meat for domestic consumption, and the number of pigs in Korea was about 9.72 million heads as of June, 2010. Meat quality is used to describe any traits which impact the consumer acceptability of fresh meat products. Meat color, firmness, water holding capacity, ultimate muscle $\mathrm{pH}_{24 \mathrm{~h}}(\mathrm{measured} 24$ hours post-mortem), shear force, and intramuscular fat percentage(IMF) are generally accepted as important indicators of meat quality and ultimately, consumer acceptance of fresh pork. The objective of this study was to estimate genetic parameters for meat quality traits in Berkshire pigs. The heritability estimates for muscle $\mathrm{pH}_{24 \mathrm{~h}}$, lightness (CIE $\mathrm{L}^{*}$ ), NPPC marbling were $0.61,0.56$ and 0.57 , respectively, The heritability estimates for drip loss, cooking loss, shear force were $0.51,0.66$ and 0.56 , respectively. The phenotypic correlations between $\mathrm{pH}_{24 \mathrm{~h}}$ and lightness (CIE L*), drip loss, cooking loss were negative, ranging from -.45 -.13 . The genetic correlations between muscle $\mathrm{pH}_{24 \mathrm{~h}}$ and lightness (CIE $\mathrm{L}^{*}$ ), drip loss were negative, ranging from $-.35 \sim-.32$. Genetic parameters obtained herein indicate that genetic improvement of muscle $\mathrm{pH}_{24 \mathrm{~h}}$ is not related to the NPPC marbling of meat, but rather to improved lightness(CIE L*) and drip loss. Genetic trends of meat quality traits showed increased muscle $\mathrm{pH}_{24 \mathrm{~h}}$ and decreased cooking loss and drip loss.
\end{abstract}

(Key words : Meat quality, Berkshire pigs, Heritability, Genetic correlation)

\section{서 론}

현재 국내에 많은 브랜드 돈육이 새롭게 출시되고 있으며, 각각 의 브랜드 돈육들은 높은 품질을 자부하고 있으나 거의 대부분의 브랜드 돈육은 품질에 대한 과학적인 근거가 부족하며, 개체별 돈 육의 육질변이, 특히 관능적 특성 변이가 매우 크기 때문에 소비자 는 브랜드 돈육의 품질을 신뢰하고 재구매하기 어려운 실정이다. 그 이유 중 한가지로 세계적으로 돼지개량은 정육량을 증가시키는 것이 주요 목적이기 때문에 돼지고기의 육질 개량은 등한시 한 결 과라고 할 수 있다(Cameron, 1990; Cliplef and McKay, 1993). 그 결과 체조성 관련 형질들은 유전능력평가를 활용하여 선발이 이 루어져왔지만(Sellier and Rothschild 1991), 돼지에 대한 육질형 질의 경우 돈군의 현황만 파악된 것이 사실이다. 특히 돼지의 육질 형질은 다양한 사전대사요인이나 사후대사요인에 영향을 받기 때문 에 정확한 육질을 예측한다는 것은 매우 어려운 일이다(Honikel,
1987; Warriss, 1987; Sellier and Monin, 1994). 그러므로 돼지 고기의 품질을 평가하기 위해서는 다양한 물리적, 화학적 요인을 평가해야 한다. 돈육의 유전능력평가를 실시하여(Goodwin, 1994; Gibson et al., 1996) 돈육의 품질에 영향을 미치는 다양한 요인에 대해 연구가 이루어져왔다(Christian and Rothschold, 1981; Stalder et al., 1998). 그 결과 사후 대사율의 척도인 사후 24시간 $\mathrm{pH}$ 와 육질형질과는 밀접한 관련이 있다는 것이 보고되었다 (Huff-Lonergan et al., 2002). 또한 유전능력평가를 하여 돈육의 품질을 개량하는 것은 육질을 평가하는데 있어 물리적, 생화학적 영향을 많이 받으므로 매우 까다롭다는 것도 보고되었다(deVries and can der Wal, 1993).

본 연구의 목적은 버크셔종의 육질을 평가하므로서 사후 대사율 의 척도인 사후 24 시간 $\mathrm{pH}$ 와 육질형질의 유전모수를 추정하여 향 후 선발에 활용하기 위한 기초자료로 이용하는데 있다.

* Corresponding author: Jong-Hyun Jung, Dasan Pig Breeding Co., San 64-2, Gasan-ri, Eubnong-eub, Namwon-si, Chunlabuk-do, 590831, Korea. Tel: +82-63-634-7651, Fax: +82-63-634-7653, E-mail: jhjjh7@snu.ac.kr 


\section{재료 및 방법}

\section{1. 공시재료}

본 연구에는 전북 남원에 위치한 D 종돈장이 2006년부터 2009 년까지 미국의 7 개 종돈장에서 모돈 300 두를 도입하여 총 5 개 유 전적 그룹으로 분리하고 그룹별 교배를 통해 2007년부터 2009년 에 태어난 순종 버크셔종 808두를 대상으로 $105 \sim 120 \mathrm{~kg}$ 에 도축 을 실시하여 공시재료로 이용하였다. 유전적 그룹은 기초돈군 조성 이 도입한 7개 종돈장을 대상으로 혈연관계가 없는 종돈장을 그룹 화 하였다. 또한 도축검사시 도축장은 전북 장수에 $\mathrm{C}$ 도축장, 충북 음성에 $\mathrm{N}$ 도축장, 충남천안의 $\mathrm{S}$ 도축장에서 도축을 실시하였다.

\section{2. 육질분석항목}

도축시 10 번째 갈비뼈 근처의 등심 표본을 채취하여 육질 분석 을 실시하였다.

(1) $\mathrm{pH} /$ 육색

시간에 따른 $\mathrm{pH}$ 와 육색의 변화는 사후 45 분, 24 시간 경과 시에 pH meter (Model 720, Thermo Orion, U.S.A)와 Chromameter (CR-300, Minolta Camera Co, Japan)를 이용하여 측정하였으며 $\mathrm{CIE} \mathrm{L*}$ 값을 측정하였다.

(2) 보수력

Filter-paper fluid uptake법을 이용하였으며 등심근을 절개하여 20 분간 방치한 후 여과지를 안전히 등심근에 포개어 유리되는 유 리 수분을 흡수 시킨 후 여과지에 흡수된 유리육즙을 측정하였다.

(3) 유즙손실율 (drip loss)

사후 24 시에 일정한 크기로 등심근을 잘라내여 무게를 잰 후 phlyethylene bag으로 육표면이 닿지 않도록 싼 후 밀봉하여 $2^{\circ} \mathrm{C}$ 에서 48 시간 방한한 다음 그 시료의 중량 감소를 \%로 산출하였다. polyethylene bag으로 육표면이 닿지 않도록 싼 후 밀봉하여 시료 의 심부온도가 $72^{\circ} \mathrm{C}$ 가 되도록 수조에서 가열한 후 그 시료의 중량 감소를 처음 중량의 \%로 산출하였다.

\section{(5) 전단력 (shear force)}

등심근을 $72^{\circ} \mathrm{C}$ 로 가열한 후 원통형 표면 채취기 (직경 $1.27 \mathrm{~cm}$ ) 로 시료를 취함(근섬유 방향과 나란하게) 이후 측정 기기 (Series IX, Instron Corp ,USA)로 원통형 시료를 자를 때(원통형 축과 수직으로 자름) 필요한 최대 힘 $(\mathrm{N})$ 을 측정하였다.

\section{2. 통계 분석 방법}

(1) 유전모수 및 육종가 추정

본 연구에서 조사한 육질형질의 유전모수 및 육종가 추정을 위해 다음과 같은 모형을 사용하였다. 모형에서 유전적그룹은 기초돈군 조성시 도입한 7 개 농장을 대상으로 혈연관계가 있는 농장들을 동 일한 그룹으로 하였다.

$$
Y_{i j k l}=\mu+L_{i}+A_{j}+Y_{k}+M_{l}+e_{i j k l}
$$

여기서,

$Y_{i j k}=\mathrm{i}$ 번째 개체의 $\mathrm{j}$ 번째 유전적 그룹에 대한 $\mathrm{j}$ 번째 도축장 에 대한 $\mathrm{k}$ 번째 도축연도에 대한 1 번째 도축월의 효과

$\mu=$ 전체평균

$\mathrm{L}_{\mathrm{i}}=\mathrm{i}$ 번째 유전적 그룹의 고정효과 : 5 개

$\mathrm{A}_{\mathrm{j}} \quad=\mathrm{j}$ 번째 도축장의 고정효과 : 3 개

$\mathrm{Y}_{\mathrm{k}} \quad=\mathrm{k}$ 번째 도축연도의 고정효과 : 3개

$\mathrm{M}_{1} \quad=1$ 번째 도축월의 고정효과 : 4개

$\mathrm{e}_{\mathrm{ijk}}=$ 각 개체에 미치는 잔차효과

각 형질의 상가적 유전효과에 대한 유전모수 및 유전상관을 추정 하기 위하여 DFREML 패키지를 이용하였다(meyer, 1987, 1988).

$\mathrm{Y}=\mathrm{Xb}+\mathrm{Zu}+\mathrm{e}$

여기서,

(4) 가열감량 (cooking loss)

Table 1. Number of animals by genetic group, slaughter year and slaughter house

\begin{tabular}{cccccc}
\hline Genetic group & No. of animals & $\begin{array}{c}\text { Slaughtered } \\
\text { year }\end{array}$ & No. of animals & $\begin{array}{c}\text { Slaughter } \\
\text { house }\end{array}$ & No. of animals \\
\hline \hline 1 & 166 & 2007 & 83 & 1 & 210 \\
2 & 127 & 2008 & 408 & 3 & 300 \\
3 & 173 & 2009 & & 3 & 298 \\
4 & 164 & & & 808 \\
5 & 178 & & 808 & & 808 \\
\hline
\end{tabular}


$\mathrm{Y}=$ 형질에 대한 관측치 벡터

$\mathrm{X}=$ 고정효과(유전적그룹, 도축장, 도축연도, 도축월)에 대한 벡터

$\mathrm{b}=$ 알려지지 않은 고정효과에 대한 추정치 벡터

$\mathrm{Z}=$ 개체에 대한 임의효과 벡터 $\sim \mathrm{N}\left(0, \mathrm{~A} \sigma_{a}^{2}\right)$

$\mathrm{u}=$ 개체에 대한 추정치 벡터

$\mathrm{e}=$ 임의 오차 벡터 $\sim \mathrm{N}\left(0, \mathrm{~A} \sigma_{a}^{2}\right)$

(2) 유전적 변화추세의 추정

유전적 변화추세는 개체의 육종가를 기준으로 각 세대의 평균값 에 대한 회귀식으로 구하였으며, 사용된 회귀모델은 다음과 같다.

$$
\begin{aligned}
& \mathrm{y}_{\mathrm{i}}=\beta_{0}+\beta_{1 \mathrm{xi}}+\mathrm{e}_{\mathrm{i}} \\
& \text { 여기서 } \\
& \mathrm{y}_{\mathrm{i}} \quad: \mathrm{i} \text { 번째 세대의 육종가 } \\
& \beta_{0} \quad \text { : 절편 } \\
& \beta_{1} \quad \text { : 세대에 대한 회귀계수 } \\
& \mathrm{x}_{\mathrm{i}} \quad: \mathrm{i} \text { 번째 세대 } \\
& \mathrm{e}_{\mathrm{i}} \quad: \text { I번째 측정된 } \mathrm{y} \text { 의 오차항 }
\end{aligned}
$$

\section{결 과}

\section{1. 일반적 특성}

본 연구에서 조사한 성별 생체중, 등지방두께, 사후 대사율 및 육질형질에 대한 평균과 표준편차를 Table 2에 제시하였다. 생체중 의 범위는 $112.86 \pm 7.69 \mathrm{~kg}$ 이고, 거세돈이 암퇘지보다 다소 높게
조사되었지만 유의적인 차이는 없었다 $(\mathrm{p}>0.05)$. 등지방두께의 범 위는 $25.41 \pm 5.64 \mathrm{~mm}$ 로 조사되었고, 거세돈이 암퇘지보다 다소 두꺼운 것으로 조사되었지만, 통계적인 유의차는 없었다 $(\mathrm{p}>0.05)$. 사후 대사율의 척도인 신선육의 산도는 도축 후 45 분 또는 1 시간 뒤의 산도, 24 시간 뒤의 산도를 측정하며 사후 45 분 $\mathrm{pH}$ 의 범위는 $5.91 \pm 0.24$, 사후 24 시간 $\mathrm{pH}$ 의 범위는 $5.82 \pm 0.24$ 이다. 육색은 소 비자가 선택시 가장 중요하게 판단되는 기준이며, 이상육 판별에 중요한 평가지표이다. 특히 명도는 이상육의 판별의 기준이 된다. $\mathrm{CIE} \mathrm{LAB}$ 색도 표현은 명도(lightness), 적색도(redness), 황색도 (yellowness)로 하는데 그 범위는 각각 $48.67 \pm 3.74,6.04 \pm 1.33$, $2.75 \pm 1.25$ 로 조사되었다.

본 연구에서 조사한 성별 육질형질에 대한 평균과 표준편차를 Table 3에 제시하였다. 근육의 보수력을 측정하는 방법은 일정 규 격 무게의 근육으로부터 수분손실(drip loss), 가열감량(cooking loss), 고속원심분리법, 필터 접촉으로 수분 흡수량 측정 방법 등이 있으나, 일정 규격 무게의 근육으로부터 수분손실(drip loss)을 측 정하는 방법이 가장 널리 이용된다. 보수력의 범위는 $58.14 \pm 3.04$ 로 조사되었고, 연도의 척도인 전단력의 경우 범위는 $3.03 \pm 0.93$ 으 로 조사되었다.

본 연구에서 조사한 육질형질에 대한 표현형상관을 Table 4에 제시하였다. 사후 대사율의 척도인 근육의 사후 24 시간 $\mathrm{pH}$ 는 육질 과의 상관성이 높은 항목으로 본 연구에서는 상강도, 보수력 및 지

\begin{tabular}{|c|c|c|c|c|c|c|c|}
\hline \multirow[b]{2}{*}{ Sex } & \multirow{2}{*}{$\begin{array}{l}\text { Live weight } \\
\qquad(\mathrm{Kg})\end{array}$} & \multirow{2}{*}{$\begin{array}{l}\text { Backfat } \\
(\mathrm{mm})\end{array}$} & \multicolumn{2}{|c|}{ Postmortem metabolic rate } & \multicolumn{3}{|c|}{ Meat quality traits } \\
\hline & & & $\begin{array}{l}\text { Muscle } \\
\mathrm{pH}_{45 \min }\end{array}$ & $\begin{array}{c}\text { Muscle } \\
\mathrm{pH}_{24 \mathrm{~h}}\end{array}$ & $\begin{array}{l}\text { Lightness } \\
\left(\mathrm{L}^{*}\right)\end{array}$ & $\begin{array}{c}\text { Redness } \\
\left(a^{*}\right)\end{array}$ & $\begin{array}{l}\text { Yellowness } \\
\left(b^{*}\right)\end{array}$ \\
\hline Total & $112.86 \pm 7.69$ & $25.41 \pm 5.64$ & $5.91 \pm 0.23$ & $5.82 \pm 0.24$ & $48.67 \pm 3.74$ & $6.04 \pm 1.33$ & $2.75 \pm 1.25$ \\
\hline Female & $112.54 \pm 7.83$ & $23.66 \pm 4.81$ & $5.89 \pm 0.22$ & $5.82 \pm 0.23$ & $48.61 \pm 3.65$ & $6.00 \pm 1.38$ & $2.81 \pm 1.25$ \\
\hline Male & $113.13 \pm 7.55$ & $26.90 \pm 5.86$ & $5.91 \pm 0.23$ & $5.82 \pm 0.26$ & $48.73 \pm 3.83$ & $6.09 \pm 1.32$ & $2.69 \pm 1.24$ \\
\hline
\end{tabular}
방함량과 정 $(+)$ 의 상관관계를 보였으며, 유리육즙량과 가열감량과 는 부 $(-)$ 의 상관관계를 나타내었다. 상강도의 경우 육색지수와 정 의 상관관계를 나타내었다. 사후 24시간 $\mathrm{pH}$ 와 명도(lightness)는 부의 상관관계를 보였고(Devol et al., 1988; Hovenier et al., 1992), 또한 유리육즙량의 경우 명도와 정의 상관관계를 보였다.

Table 2. Comparison of live weight, backfat, postmortem metabolic rate and meat quality traits by sex

Table 3. Comparison of the meat quality traits by sex

\begin{tabular}{cccccc}
\hline \multirow{2}{*}{ Sex } & \multicolumn{5}{c}{ Meat quality traits } \\
\cline { 2 - 6 } Total & $58.14 \pm 3.04$ & $2.62 \pm 1.14$ & $4.52 \pm 1.99$ & $26.72 \pm 4.05$ & $3.03 \pm 0.93$ \\
Female & $58.43 \pm 3.03$ & $2.40 \pm 1.09$ & $4.40 \pm 1.87$ & $26.71 \pm 4.01$ & $3.04 \pm 0.92$ \\
Male & $57.85 \pm 3.03$ & $2.84 \pm 1.16$ & $4.64 \pm 2.10$ & $26.73 \pm 4.10$ & $3.03 \pm 0.95$ \\
\hline \hline
\end{tabular}

*WHC : Water Holding Capacity, ** NPPC : National Pork Producers Council 
Table 4. The phenotypic correlations between meat quality measurements

\begin{tabular}{|c|c|c|c|c|c|c|c|c|c|c|}
\hline \multirow{2}{*}{ Traits } & \multicolumn{2}{|c|}{$\begin{array}{l}\text { Postmortem } \\
\text { metabolic rate }\end{array}$} & \multicolumn{8}{|c|}{ Meat quality traits } \\
\hline & $\begin{array}{l}\text { Muscle } \\
\mathrm{pH}_{45 \min }\end{array}$ & $\begin{array}{c}\text { Muscle } \\
\mathrm{pH}_{24 \mathrm{~h}}\end{array}$ & $\begin{array}{l}\text { Lightness } \\
\left(\mathrm{L}^{*}\right)\end{array}$ & $\begin{array}{l}\text { Redness } \\
\left(a^{*}\right)\end{array}$ & $\begin{array}{c}\text { Yellowness } \\
\left(b^{*}\right)\end{array}$ & $\mathrm{WHC}^{*}$ & $\begin{array}{l}\text { NPPC } \\
\text { marbling }\end{array}$ & Drip loss & $\begin{array}{c}\text { Cooking } \\
\text { loss }\end{array}$ & $\begin{array}{c}\text { Shear } \\
\text { force }(\mathrm{N})\end{array}$ \\
\hline Muscle $\mathrm{pH}_{45 \min }$ & & $\begin{array}{r}0.40 \\
(0.0001)\end{array}$ & $\begin{array}{l}-0.03 \\
(0.73)\end{array}$ & $\begin{array}{l}-0.18 \\
(0.04)\end{array}$ & $\begin{array}{l}-0.05 \\
(0.57)\end{array}$ & $\begin{array}{l}-0.01 \\
(0.99)\end{array}$ & $\begin{array}{l}-0.05 \\
(0.60)\end{array}$ & $\begin{array}{l}-0.23 \\
(0.01)\end{array}$ & $\begin{array}{r}0.15 \\
(0.09)\end{array}$ & $\begin{array}{l}-0.23 \\
(0.01)\end{array}$ \\
\hline Muscle $\mathrm{pH}_{24 \mathrm{~h}}$ & & & $\begin{array}{r}-0.42 \\
(0.0001)\end{array}$ & $\begin{array}{r}-0.13 \\
(0.0001)\end{array}$ & $\begin{array}{r}-0.20 \\
(0.0001)\end{array}$ & $\begin{array}{r}0.33 \\
(0.0001)\end{array}$ & $\begin{array}{r}0.16 \\
(0.0001)\end{array}$ & $\begin{array}{r}-0.45 \\
(0.0001)\end{array}$ & $\begin{array}{r}-0.13 \\
(0.0001)\end{array}$ & $\begin{array}{r}-0.30 \\
(0.0001)\end{array}$ \\
\hline Lightness $\left(\mathrm{L}^{*}\right)$ & & & & $\begin{array}{l}-0.03 \\
(0.08)\end{array}$ & $\begin{array}{r}0.53 \\
(0.0001)\end{array}$ & $\begin{array}{r}-0.21 \\
(0.0001)\end{array}$ & $\begin{array}{r}0.15 \\
(0.0001)\end{array}$ & $\begin{array}{r}0.36 \\
(0.0001)\end{array}$ & $\begin{array}{r}0.28 \\
(0.0001)\end{array}$ & $\begin{array}{r}0.04 \\
(0.03)\end{array}$ \\
\hline Redness $\left(\mathrm{a}^{*}\right)$ & & & & & $\begin{array}{r}0.40 \\
(0.0001)\end{array}$ & $\begin{array}{r}0.06 \\
(0.02)\end{array}$ & $\begin{array}{r}0.22 \\
(0.0001)\end{array}$ & $\begin{array}{r}0.08 \\
(0.003)\end{array}$ & $\begin{array}{r}0.09 \\
(0.001)\end{array}$ & $\begin{array}{r}0.01 \\
(0.43)\end{array}$ \\
\hline Yellowness (b*) & & & & & & $\begin{array}{r}0.31 \\
(0.0001)\end{array}$ & $\begin{array}{r}0.34 \\
(0.0001)\end{array}$ & $\begin{array}{r}0.01 \\
(0.64)\end{array}$ & $\begin{array}{r}0.12 \\
(0.0001)\end{array}$ & $\begin{array}{l}-0.03 \\
(0.09)\end{array}$ \\
\hline WHC & & & & & & & $\begin{array}{r}0.19 \\
(0.0001) \\
\end{array}$ & $\begin{array}{r}-0.41 \\
(0.0001)\end{array}$ & $\begin{array}{r}-0.26 \\
(0.0001) \\
\end{array}$ & $\begin{array}{r}-0.29 \\
(0.0001)\end{array}$ \\
\hline NPPC marbling & & & & & & & & $\begin{array}{l}-0.07 \\
(0.02)\end{array}$ & $\begin{array}{c}-0.01 \\
(0.76) \\
\end{array}$ & $\begin{array}{r}-0.18 \\
(0.0001) \\
\end{array}$ \\
\hline Drip loss & & & & & & & & & $\begin{array}{r}0.27 \\
(0.0001)\end{array}$ & $\begin{array}{r}0.34 \\
(0.0001)\end{array}$ \\
\hline Cooking loss & & & & & & & & & & $\begin{array}{r}0.20 \\
(0.0001)\end{array}$ \\
\hline
\end{tabular}

Shear force $(\mathrm{N})$

* WHC : Water Holding Capacity, **NPPC : National Pork Producers Council

P-values for difference from zero in parentheses.

\section{2. 육질형질의 유전모수추정}

Table 5에는 사후 대사율의 척도인 근육의 사후 45 분, 24 시간 $\mathrm{pH}$ 와 육질형질에 대한 유전분산, 환경분산 및 유전력을 나타내었 다. 사후 대사율의 척도인 사후 45 분 $\mathrm{pH}$ 와 사후 24 시간 $\mathrm{pH}$ 의 유 전력은 각각 0.60 과 0.61 로 추정하였다. NPPC (2000)에서는 사후 24 시간 $\mathrm{pH}$ 의 유전력을 0.53 이라고 보고하여 본 연구결과와 비슷 하였다. 그러나 Suzuki (2005)는 0.07 \pm 0.02 , Sellier (1998)는 0.21 이라고 보고하여 본 연구 결과보다 낮게 보고하였다. 사후 24시간 $\mathrm{pH}$ 는 근육의 품질을 평가할 수 있는 척도로서, 육질개량에 있어 육종가를 활용할 경우 선발 효과는 크게 나타날 것이다. 명도 (lightness)의 유전력은 0.56 으로 추정되어, $\mathrm{NPPC}$ 에서 보고한 0.44 와 비슷하였다. 그러나 Suzuki (2005)는 0.16 \pm 0.02 , Sellier (1998)는 0.28로 보고하여 본 연구결과 보다는 낮게 보고하였다. 본 연구에서 근내지방도의 유전력은 0.57 로 추정하였다. Knapp (1997)는 근내지방도 유전력을 0.42, Larzul(1997)은 0.44, Sellier (1998)는 0.50으로 보고하여 본 연구결과와 비슷하게 보고
하였다. 유리육즙량과 가열감량의 유전력은 각각 0.51 과 0.66 으로 추정하였다. Hovenier (1993)와 Sellier (1998)는 유리육즙량과 가 열감량의 유전력이 각각 $0.00 \sim 0.63$ 과 $0.00 \sim 0.51$ 라고 보고하여 본 연구 결과와 비슷한 결과를 보였다. 연도의 척도인 전단력(shear force)의 유전력은 0.56 으로 추정하였으며, 이 결과는 Suzuki (2005)가 보고한 $0.45 \pm 0.02$ 과 비슷하였다, 그러나 Hovenier (1993)가 보고한 0.21 0.37과 Sellier (1998)가 보고한 0.26 보다 는 다소 높게 추정하였다. 본 연구에서 추정한 육질형질의 유전력 은 높아 향후 육질개량에 있어 육종가 (breeding value)를 기반으 로 선발할 경우 유전적 개량량은 크게 나타날 것으로 사료된다.

Table 6에는 사후 대사율의 척도인 근육의 사후 45 분 $\mathrm{pH}, 24$ 시 간 $\mathrm{pH}$ 와 육질형질에 대한 유전상관을 제시하였다. 사후 대사율의 척도인 사후 24 시간 $\mathrm{pH}$ 와 명도, 적색도, 황색도간의 유전상관은 각각 $-0.32,-0.11,-0.22$ 로 (부)의 상관관계로 조사되었고, 이 결과는 Suzuki(2005)도 비슷한 결과를 보고하였다. 또한 사후 24 시간 $\mathrm{pH}$ 와 가열감량과 전단력은 각각 -0.35 와 -0.18 로 부 $(-)$ 의 상관관계로 조사되었다. PSE 돈육 판별척도인 명도(lightness)와 
Table 5. The genetic variance, environmental variance, heritability for posmortem metabolic rate and meat quality traits

\begin{tabular}{|c|c|c|c|}
\hline & $\begin{array}{l}\text { Genetic } \\
\text { variance }\end{array}$ & $\begin{array}{c}\text { Environmental } \\
\text { variance }\end{array}$ & $\begin{array}{c}\text { Heritability } \\
\quad\left(h^{2}\right)\end{array}$ \\
\hline \multicolumn{4}{|l|}{ Postmortem metabolic rate } \\
\hline Muscle $\mathrm{pH}_{45 \min }$ & 0.0491 & 0.0326 & 0.60 \\
\hline Muscle $\mathrm{pH}_{24 \mathrm{~h}}$ & 0.0327 & 0.0206 & $\begin{array}{c}0.61 \\
(0.53)\end{array}$ \\
\hline \multicolumn{4}{|l|}{ Meat quality traits } \\
\hline Lightness $\left(\mathrm{L}^{*}\right)$ & 9.0260 & 7.1420 & $\begin{array}{c}0.56 \\
(0.44) \\
\end{array}$ \\
\hline Redness (a*) & 1.1890 & 0.8551 & 0.58 \\
\hline Yellowness $\left(b^{*}\right)$ & 0.9835 & 0.6004 & 0.62 \\
\hline Water holding capacity & 3.4990 & 1.9300 & 0.64 \\
\hline NPPC marbling & 1.0460 & 0.7877 & $\begin{array}{c}0.57 \\
(0.66)\end{array}$ \\
\hline Drip loss & 2.3320 & 2.2360 & $\begin{array}{c}0.51 \\
(0.22)\end{array}$ \\
\hline Cooking loss & 11.5600 & 5.8910 & 0.66 \\
\hline Shear force $(\mathrm{N})$ & 0.4516 & 0.4238 & $\begin{array}{c}0.56 \\
(0.37)\end{array}$ \\
\hline
\end{tabular}

※ ( )는 National Pork Producer Council, 2000.

Table 6 . The genetic correlations between meat quality measurements

\begin{tabular}{|c|c|c|c|c|c|c|c|c|c|c|}
\hline \multirow{2}{*}{ Traits } & \multicolumn{2}{|c|}{$\begin{array}{l}\text { Postmortem } \\
\text { metabolic rate }\end{array}$} & \multicolumn{8}{|c|}{ Meat quality traits } \\
\hline & $\begin{array}{l}\text { Muscle } \\
\mathrm{pH}_{45 \min }\end{array}$ & $\begin{array}{c}\text { Muscle } \\
\mathrm{pH}_{24 \mathrm{~h}}\end{array}$ & $\begin{array}{l}\text { Lightness } \\
\left(\mathrm{L}^{*}\right)\end{array}$ & $\begin{array}{c}\text { Redness } \\
\left(a^{*}\right)\end{array}$ & $\begin{array}{l}\text { Yellowness } \\
\left(\mathrm{b}^{*}\right)\end{array}$ & WHC* & $\begin{array}{c}\text { NPPC } \\
\text { marbling }\end{array}$ & Drip loss & $\begin{array}{c}\text { Cooking } \\
\text { loss }\end{array}$ & $\begin{array}{l}\text { Shear force } \\
\text { (N) }\end{array}$ \\
\hline Muscle $\mathrm{pH}_{45 \min }$ & & $\begin{array}{c}0.11 \\
(<.0001)\end{array}$ & $\begin{array}{c}0.02 \\
(0.0573) \\
\end{array}$ & $\begin{array}{c}0.06 \\
(<.0001) \\
\end{array}$ & $\begin{array}{c}0.08 \\
(<.0001)\end{array}$ & $\begin{array}{c}0.05 \\
(0.0004) \\
\end{array}$ & $\begin{array}{c}0.04 \\
(0.0021) \\
\end{array}$ & $\begin{array}{c}-0.01 \\
(0.5265)\end{array}$ & $\begin{array}{c}0.01 \\
(0.6668) \\
\end{array}$ & $\begin{array}{c}-0.08 \\
(<.0001)\end{array}$ \\
\hline Muscle $\mathrm{pH}_{24 \mathrm{~h}}$ & & & $\begin{array}{c}-0.32 \\
(<.0001) \\
\end{array}$ & $\begin{array}{c}-0.11 \\
(<.0001) \\
\end{array}$ & $\begin{array}{c}-0.22 \\
(<.0001) \\
\end{array}$ & $\begin{array}{c}0.23 \\
(<.0001) \\
\end{array}$ & $\begin{array}{c}0.06 \\
(<.0001) \\
\end{array}$ & $\begin{array}{c}-0.35 \\
(<.0001) \\
\end{array}$ & $\begin{array}{c}0.04 \\
(0.0025) \\
\end{array}$ & $\begin{array}{c}-0.18 \\
(<.0001) \\
\end{array}$ \\
\hline Lightness (L*) & & & & $\begin{array}{c}0.11 \\
(<.0001) \\
\end{array}$ & $\begin{array}{c}0.61 \\
(<.0001) \\
\end{array}$ & $\begin{array}{c}-0.28 \\
(<.0001) \\
\end{array}$ & $\begin{array}{c}0.20 \\
(<.0001) \\
\end{array}$ & $\begin{array}{c}0.55 \\
(<.0001) \\
\end{array}$ & $\begin{array}{c}0.29 \\
(<.0001) \\
\end{array}$ & $\begin{array}{c}0.11 \\
(<.0001) \\
\end{array}$ \\
\hline Redness (a*) & & & & & $\begin{array}{c}0.57 \\
(<.0001) \\
\end{array}$ & $\begin{array}{c}-0.09 \\
(<.0001) \\
\end{array}$ & $\begin{array}{c}0.27 \\
(<.0001) \\
\end{array}$ & $\begin{array}{c}0.18 \\
(<.0001) \\
\end{array}$ & $\begin{array}{c}0.22 \\
(<.0001) \\
\end{array}$ & $\begin{array}{c}0.03 \\
(0.0262) \\
\end{array}$ \\
\hline Yellowness (b*) & & & & & & $\begin{array}{c}-0.05 \\
(<.0001)\end{array}$ & $\begin{array}{c}0.39 \\
(<.0001)\end{array}$ & $\begin{array}{c}0.31 \\
(<.0001)\end{array}$ & $\begin{array}{c}0.36 \\
(<.0001)\end{array}$ & $\begin{array}{c}-0.01 \\
(0.6612)\end{array}$ \\
\hline WHC & & & & & & & $\begin{array}{c}0.13 \\
(<.0001) \\
\end{array}$ & $\begin{array}{c}-0.39 \\
(<.0001) \\
\end{array}$ & $\begin{array}{c}-0.01 \\
(0.8489) \\
\end{array}$ & $\begin{array}{c}-0.31 \\
(<.0001)\end{array}$ \\
\hline NPPC marbling & & & & & & & & $\begin{array}{c}-0.03 \\
(0.0381)\end{array}$ & $\begin{array}{c}0.08 \\
(<.0001)\end{array}$ & $\begin{array}{c}-0.22 \\
(<.0001)\end{array}$ \\
\hline Drip loss & & & & & & & & & $\begin{array}{c}0.08 \\
(<.0001) \\
\end{array}$ & $\begin{array}{c}0.45 \\
(<.0001) \\
\end{array}$ \\
\hline Cooking loss & & & & & & & & & & $\begin{array}{c}0.05 \\
(<.0001) \\
\end{array}$ \\
\hline
\end{tabular}

Shear force $(\mathrm{N})$

* WHC : Water holding capacity, **NPPC : National Pork Producers Council

$\mathrm{P}$-values for difference from zero in parentheses 
NPPC marbling, 유즙손실량(drip loss), 가열감량, 전단력과의 유 전상관은 각각 $0.20,0.55,0.29$ 및 0.11 로 정 $(+)$ 의 상관관계로 조 사되었다. NPPC marbling과 유즙손실량, 가열감량과 유전상관은 각각 $-0.03,0.08$ 로 상관도가 다소 낮은 것으로 조사되었지만, 연 도의 척도인 전단력과 NPPC marbling과는 -0.22 로 조사되었다. 본 연구 결과는 Suzuki (2005)가 보고한 결과와 비슷하였다. 유즙 손실량과 가열감량의 유전상관은 0.08 로 조사되었고, 본 결과는

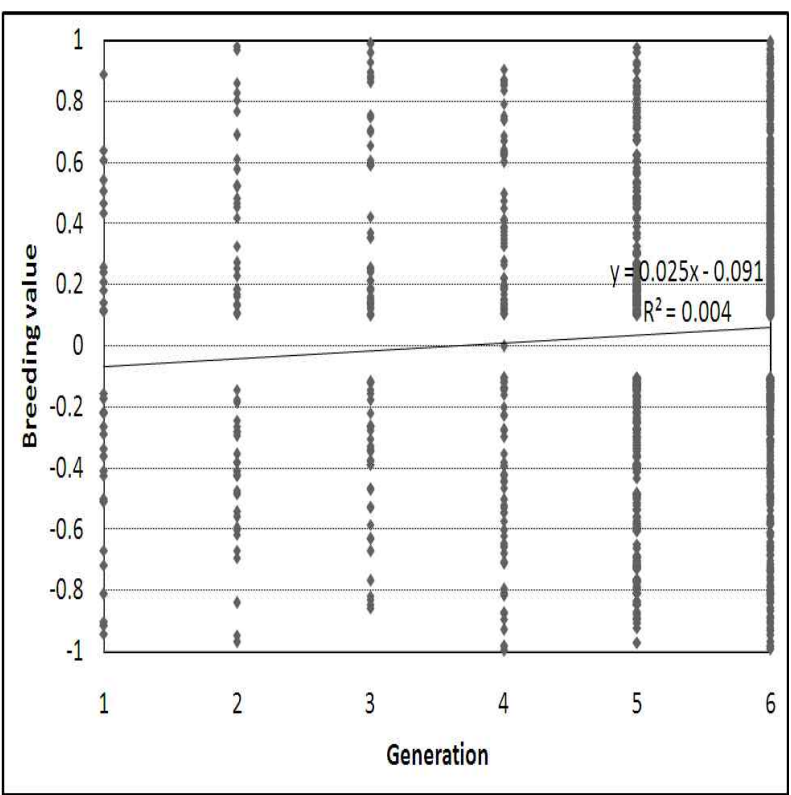

Fig. 1. Changes of breeding value expressed per additivie genetic SD in $\mathrm{ph}_{24 \mathrm{~h}}$.

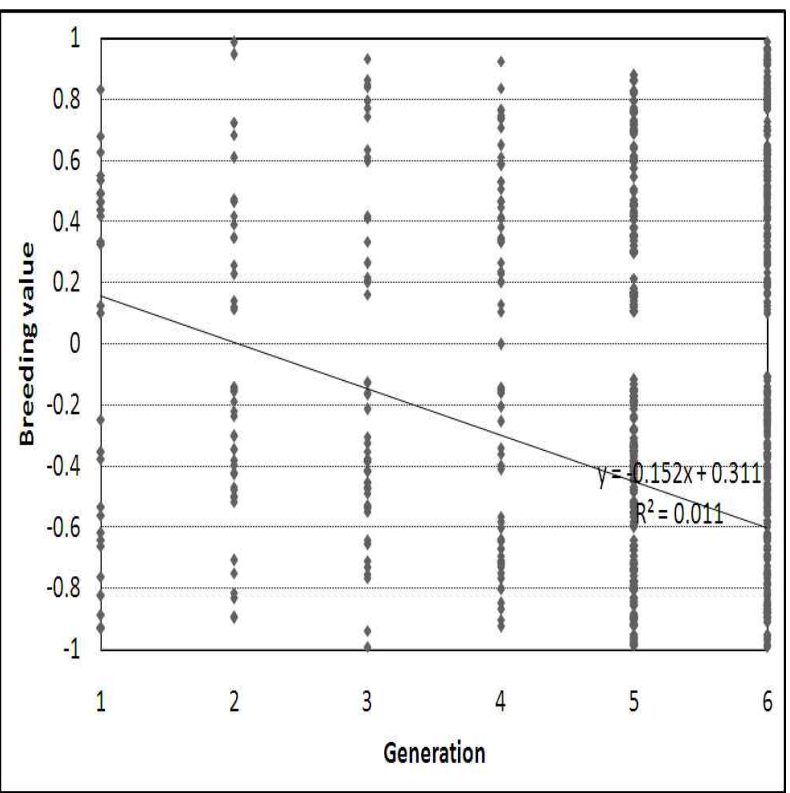

Fig. 2. Changes of breeding value expressed per additivie genetic SD in lightness.
Suzuki (2005)가 보고한 0.01과 비슷하였지만, Sellier(1998)가 보 고한 0.66 보다는 낮게 조사되었다.

Fig, 1과 2에는 사후 24시간 $\mathrm{pH}$ 와 명도(lightness)의 유전적 변 화 추이를 추정하여 나타내었다. 매 세대별 사후 24 시간 $\mathrm{pH}$ 는 0.0255 증가하였고, 명도는 세대당 0.1523 씩 감소하는 것으로 조 사되었다.

Fig. 3과 4에는 NPPC marbling과 유즙손실량(drip loss)의 유

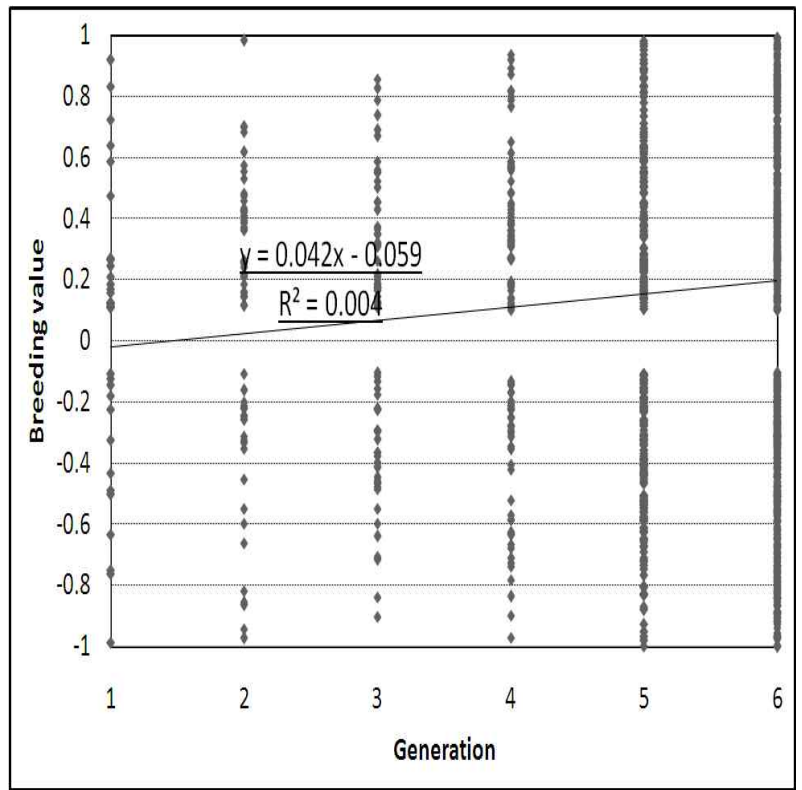

Fig. 3. Changes of breeding value expressed per additivie genetic SD in NPPC marbling.

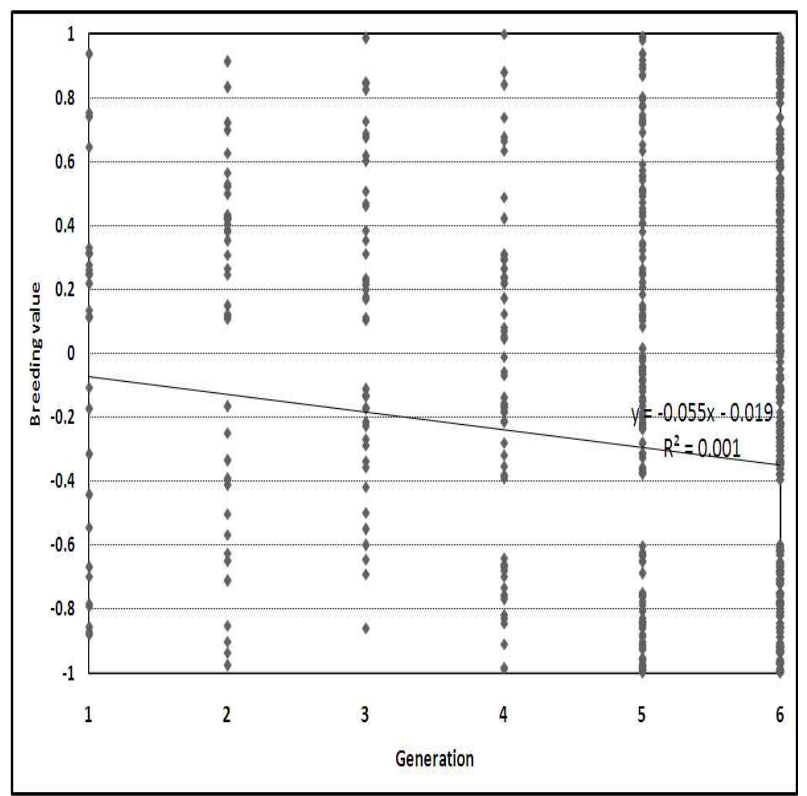

Fig. 4. Changes of breeding value expressed per additivie genetic SD in drip loss. 
전적 변화 추이를 추정하여 나타내었다. 매 세대별 $\mathrm{NPPC}$ marbling은 0.0429 증가하였고, 유즙손실량은 세대당 0.055 씩 감 소하는 것으로 조사되었다.

Fig. 5과 6 에는 가열감량과 전단력의 유전적 변화 추이를 추정 하여 나타내었다. 매 세대별 가열감량과 전단력이 각각 0.0837 과 0.0468 씩 감소하는 것으로 조사되었다.

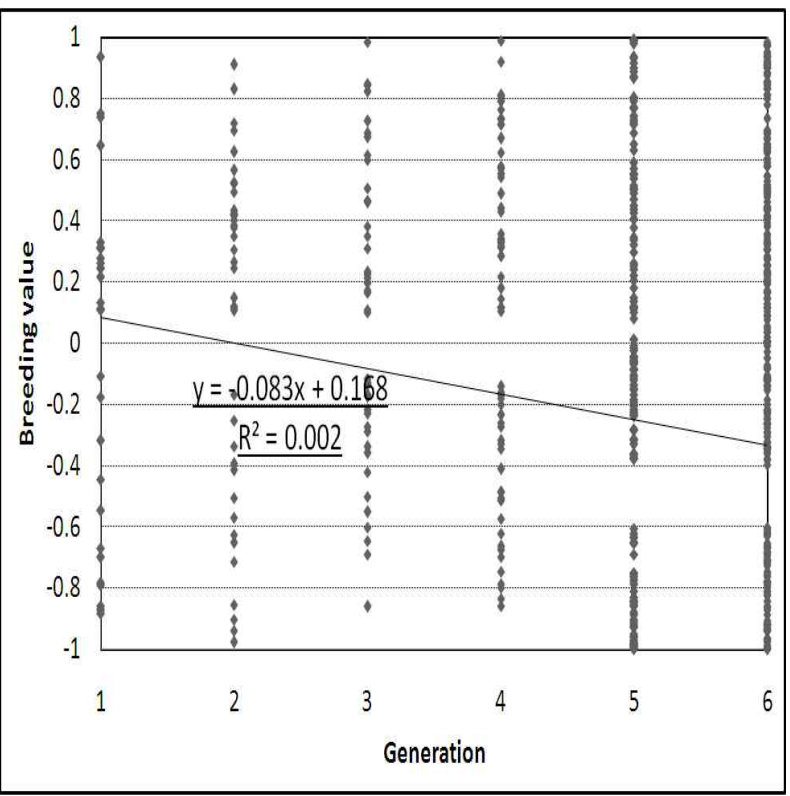

Fig. 5. Changes of breeding value expressed per additivie genetic SD in cooking loss.

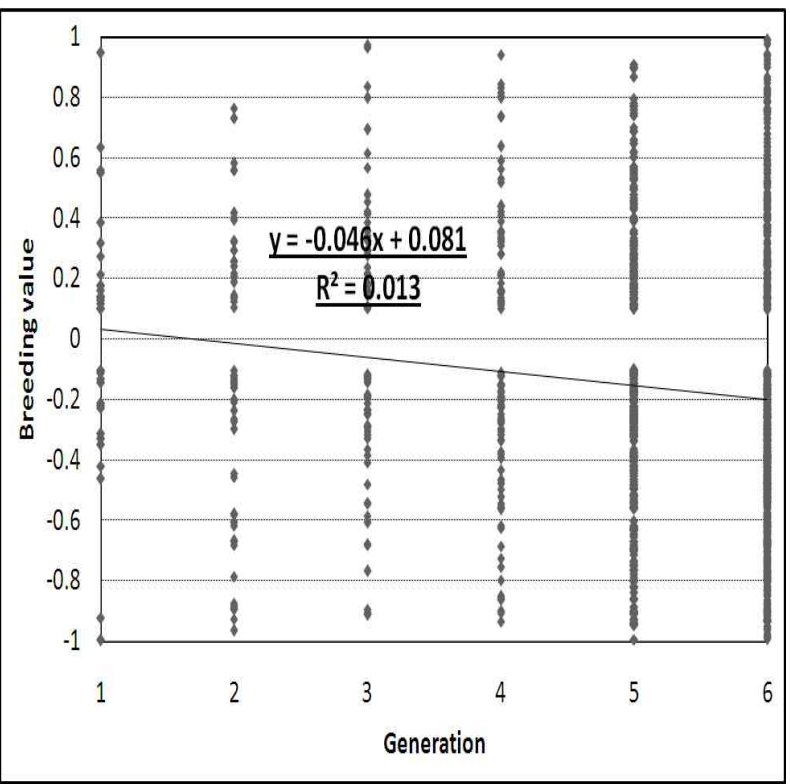

Fig. 6. Changes of breeding value expressed per additivie genetic SD in shear force.

\section{요 약}

본 연구는 2004년 2008년에 미국에서 도입한 버크셔종의 육질 형질에 대한 유전적 특성을 파악하고, 향후 선발에 이용한 유전적 그릅(genetic group)을 분리하여 선발 및 교배계획을 체계적으로 세워 효과를 극대화시키는 전략을 세우고자 수행하였다. 그 결과 사후 대사율의 척도인 근육의 사후 45 분 $\mathrm{pH}, 24$ 시간 $\mathrm{pH}$ 에 대한 유전력은 각각 0.60 과 0.61 로 높게 조사되었다. 육색의 척도인 명 도, 적색도 및 황색도의 유전력은 $0.56,0.58$ 및 0.62 로 조사되었 다. 근내지방도, 유리육즙량과 가열감량에 대한 유전력은 각각 $0.57,0.51$ 및 0.66 으로 조사되었다. 본 연구 결과로 미루어 볼 때 육질형질의 개량에 있어 육종가를 기초로 하여 선발에 활용할 경우 유전적 개량량은 크게 나타날 것으로 사료된다. 또한 사후 대사율 의 척도인 $\mathrm{pH}$ 와 육질형질과의 상관도는 높은 연관성이 존재하므 로, 종돈장에서 육질형질을 개량하고자 한다면 육종가를 기반으로 한 선발지수(selection index)를 활용하면 매우 효과적일 것으로 필자는 사료된다. 그러나 본 연구에 활용된 자료는 유전모수를 추 정하는데 다소 부족한 것은 사실이지만 국내 최초로 돼지의 육질형 질에 대한 유전모수를 추정하는데 있어 매우 의미가 있다고 할 수 있다.

(주제어: 버크셔종, 유전력, 상관도, 육종가)

$$
\text { 사 사 }
$$

이 논문은 농촌진흥청 바이오그린 21 연구비 지원에 의해 수행 되었다.

\section{인 용 문 헌}

Cameron, N. D. 1990. Genetic and phenotypic parameters for carcass traits, meat and eating quality traits in pigs. Livest. Prod. Sci. 26:119-135.

Christian, L. L. and Rothschil, M. F. 1991. Performance and carcass characteristic of normal, stress-carrier, and stress-susceptible swine. Publication AS-528-F. Iowa State University Cooperative Exstension Service, Ames.

Cliplef, R. L. and McKay, R. M. 1993. Carcass quality characteristics of swine selected for reduced backfat thickness and increased growth rate. Can. J. Anim. Sci. 73:483-494.

DeVol, D. L., Mckeith, F. K., Bechtel, P. J., Novakofski, J., Shanks, R. D. and Carr, T. R. 1988. Variation in composition and palatability traits and relationships between muscle characteristics and palability in a random sample of pork carcasses. J. Anim. Sci. 66:385-395.

Gibson, J. P., Aker, C. A. and Ball, R. O. 1998. Proceeding fo the Omtario Pork Carcass Appraisal Project Symposium. Omtario 
Swine Improvement Inc. Guelph, Ontario, Canata.

Goodwin, R. N. 1994. Genetic parameters of pork quality traits. Ph.D. Thesis. Iowa State University, Ames.

Honikel, K. O. 1997. The influence of chilling on meat quality attributes of fast glycolysing pork muscle. In; P. V. Tarrent, G. Eikelenboom, and G. Monin 9ed.) Evaluation and control of meat Quality in Pigs. pp273-284.

Hovenier, R., Kanis, E., van Asseldonk, T. and Westerink, N. G. 1992. Genetic parameters of pig meat quality traits ina halothane negative population. Livest. Prob. Sci. 32:309-321.

Hovenier, R., Kanis, E., van Asseldonk, T. and Westerink, N. G. 1993. Breeding for pig meat quality in halothane negative populations-A review. Pig News inf. 14:17N-25N.

Huff-Lonergan, E., Bass, T. J., Malek, M., Dekkers, J. C. M., Prusa, K. and Rothschild, M. F. 2002. Correlations among selected pork quality traits. J. Anim. Sci. 80:617-627.

Knapp, P., William, A. and Solkner, J. 1997. Genetic parameters for lean meat content and meat quality traits in different pig breeds. Livest. Prob. Sci. 52:69-73.

Larzul, C., Lefaucheur, L., Ecolan, P., Gogue, J., Talmant, A., Sellier, P., Le Roy, P. and Monin, G. 1997. Phenotypic and genetic parameters for longissimus muscle fiber characteristics in relation to growth carcass, and meat quality traits in Large White pigs. J. Anim. Sci. 75:3126-3137.

Meyer, K. 1987a. Restricted Maximum Likelihood (REML) programs for the analysis of animal breeding data. Program notes prepared for a workshop in Orange, NSW, March 2--6, 1987. Mimeo.
55.

Meyer, K. 1988c. Estimation of variance components for Individual Animal Models II. Multivariate analyses. Genet. Sel. Evol. (submitted).

Sellier, P. 1998. Genetic of meat and carcass traits. Pages in 463-510 in The Genetics of the Pigs. M. F. Rothschild, and A. Rubinsky, ed. CAB Int, New York, NY.

Sellier, P. and Monin 1994. Genetics of Meat Quality; A review. 1994. J. Muscle Foods 5:187-219.

Sellier, P. and Rothschild, M. F. 1991. Breed identificatrion and development in pigs. In; K. Maijala (ed.) Genetic resources Elsevier Science Publishier, Amsterdam, The Netherlands.

Stalder, K. J., Maya, J., Christian, L. L., Moeller, S. J. and Prusa, K. J. 1998. Effectrs of preslaughter management on the quality of carcasses from porcine sterss syndrome heterozygous marker hogs. J. Anim. Sci. 76:2435-2443.

Suzukim, K., Irie, M., Kadowaki, H., Shibata, T., Shibat, M., Kumagai, M. and Nishida, A. 2005. Genetic parameter estimates of meat quality traits in Duroc pigs selected for average daily gain, longissmus muscle area, backfat thickness, and intramuscular fat content. J. Anim. Sci. 83:2058-2065.

Warriss, P. D. 1997. the effect of time and condition of trasport and lairge on pig meat quality. In; P. V. Tarrent, G. Eikelenboom, and G. Monin (eds) Evaluation and Control of Meat Quality in Pigs. pp245-264.

(Received Dec. 27, 2010; Revised Aug. 10, 2011; Accepted Aug. 12, 2011) 